\title{
PERANCANGAN SISTEM INFORMASI INVENTORY PT. ABC
}

\author{
Iphov K. Sriwana ${ }^{1}$, Maria Loura Christia ${ }^{2}$, Ellytasia $^{2}$ dan Gebriel Chandiawan ${ }^{2}$ \\ ${ }^{1}$ Program Studi Teknik Industri Universitas Esa Unggul \\ ${ }^{2}$ Program Studi Teknik Industri Universitas Tarumanagara \\ e-mail: marialoura24@gmail.com, ellytasia96@gmail.com, gebriel.chandiawan@gmail.com
}

\begin{abstract}
ABSTRAK
PT. ABC bergerak dalam bidang penyediaan barang agrikultur. Saat ini, pencatatan laporan persediaan di PT. ABC belum optimal sehingga menyebabkan kinerja perusahaan menjadi terhambat. Penelitian ini bertujuan untuk menganalisa dan merancang sebuah sistem inventori berbasis web yang dapat menyajikan informasi yang dibutuhkan oleh top management dan staf perusahaan agar dapat mengetahui dan mengendalikan jumlah stock barang yang terdapat dalam gudang. Alat pengembangan yang digunakan penelitian ini menggunakan PHP.5.6.3 sebagai bahasa pemrograman dan MySQL versi 5.6.21 sebagai manajemen database sistem inventori serta menggunakan bantuan software ArgoUML. Manfaat yang dapat diperoleh dalam sistem inventori ini adalah tim manajemen dapat mengetahui siapa saja customer perusahaan PT. ABC dan item apa saja yang paling banyak dibutuhkan, sehingga memudahkan tim manajemen untuk memutuskan strategi manajemen inventori perusahaan pada tahun berikutnya.
\end{abstract}

Kata kunci: Manajemen Sistem Inventori, ArgoUML, PHP dan MySQL

\begin{abstract}
$P T . A B C$ is engaged in the supply of agricultural goods. Currently, the recording inventory reports at PT. ABC has not been optimal, causing the company's performance to be hampered. This study aims to analyze and design a web-based inventory system that can provide information needed by top management and staff of the company in order to know and control the amount of stock of goods contained in the warehouse. The development tool used in this research is using PHP.5.6.3 as programming language and MySQL version 5.6.21 as an inventory system database management and uses ArgoUML software assistance. The benefits that can be obtained in this inventory system are that the management team can find out who the company ABC's customers are and what items are most needed, making it easier for the management team to decide on the company's inventory management strategy the following year.
\end{abstract}

Keywords: Inventory Management System, ArgoUML, PHP and MySQL

\section{PENDAHULUAN}

Seiring dengan berkembangnya zaman, teknologi informasi menjadi suatu sarana yang penting dalam meningkatkan efektivitas dan efisiensi kegiatan dalam suatu perusahaan. Hampir semua bidang bisnis menggunakan sistem informasi dalam menunjang kegiatan operasionalnya [1]. Pengambilan keputusan secara tepat menjadi salah satu tahapan penting dalam melaksanakan suatu kegiatan operasional. Berbagai bentuk informasi dan data sangat diperlukan agar perusahaan dapat mengambil keputusan secara tepat dan cepat [2]. Pengambilan keputusan merupakan peranan manajemen yang paling penting. Tersedianya sumber informasi yang reliabel merupakan komponen kunci bagi pembuatan manajemen [3]. Tidak dapat dipungkiri lagi bahwa kebutuhan akan informasi saat ini menjadi prioritas utama bagi para pengambil keputusan dalam mengelola perusahaan. Berdasarkan realita tersebut, maka kebutuhan informasi pada perusahaan-perusahaan saat ini telah beralih menjadi kebutuhan yang utama. Organisasi selalu membutuhkan sistem-sistem untuk mengumpulkan, mengolah menyimpan, melihat kembali dan menyalurkan informasi-informasi [4]. Informasi yang biasanya didapatkan dengan cara yang tradisional atau manual, sudah tidak dapat digunakan lagi secara maksimal dalam memenuhi kebutuhan perusahaan karena perusahaan menginginkan adanya informasi yang akurat dan cepat.

Kualitas informasi memegang peranan penting dalam suatu perusahaan untuk mengetahui kegiatan apa saja yang telah terjadi 
di dalam perusahaan [5]. Melakukan evaluasi apakah kegiatan sudah sesuai dengan apa yang telah direncanakan dan menjamin agar data tersebut dapat diolah secara efisien menjadi informasi yang akurat. Salah satu teknologi informasi yang dapat dimanfaatkan adalah komputer. Dalam sebuah instansi, komputer merupakan sarana yang sangat dibutuhkan dalam menyelesaikan pekerjaan perusahaan dengan cepat dan hasil yang sangat memuaskan. Kemampuan dalam mengolah informasi dengan sistem teknologi informasi yang dibangun juga sangat menentukan keunggulan bersaing (competitive advantage) perusahaan [6].

PT. ABC merupakan sebuah perusahaan yang bergerak dalam bidang penyediaan barang agrikultur. Sistem yang berjalan dalam perusahaan masih memiliki banyak kekurangan dan kelemahan seperti memerlukan waktu yang cukup lama untuk pengiriman surat perintah kerja, penyusunan laporan yang masih manual menyebabkan kinerja perusahaan menjadi terhambat dan belum mampu menunjang segala kebutuhan yang diinginkan perusahaan. Untuk mengatasi berbagai permsalahan tersebut, maka dilakukan penelitian terhadap pengaturan sistem inventori barang pada PT. ABC, sehingga informasi yang dihasilkan cepat, tepat dan akurat. Oleh karena itu diambil tema "Pengembangan Sistem Informasi Inventori pada PT. ABC".

Tujuan penelitian adalah untuk merancang desain aplikasi yang menarik dan user friendly untuk memudahkan karyawan PT. ABC dalam mengolah data barang, menyajikan informasi barang yang akurat dan menyajikan laporan yang cepat sesuai kebutuhan perusahaan.

\section{METODOLOGI PENELITIAN}

Dalam penelitian ini, pengembangan sistem dilakukan dengan menggunaan pendekatan RAD (Rapid Application Development) dan UML Diagram (Use case diagram, Class diagram, Sequence Diagram dan Activity diagram). Perancangan perangkat lunak berfokus pada pembuatan program perangkat lunak termasuk struktur data, arsitektur perangkat lunak, representasi antar muka dan prosedur pengodean. Flowchart metodologi penelitian yang dilakukan dapat dilihat pada Gambar 1.

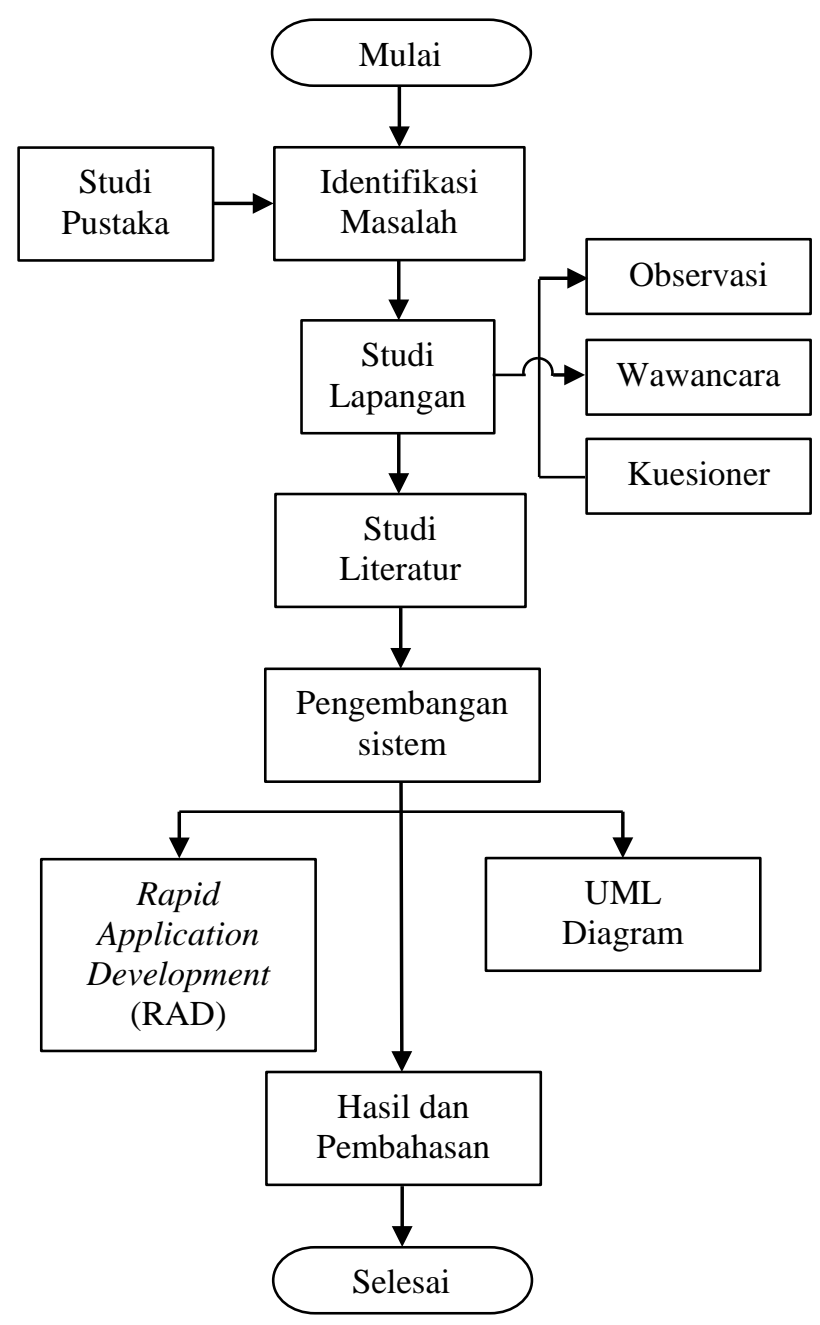

Gambar 1. Flowchart Metodologi Penelitian

\section{HASIL DAN PEMBAHASAN}

Berdasarkan kebutuhan sistem, perangkat lunak yang dibangun harus memenuhi kebutuhan berikut: mampu memudahkan perusahaan dalam proses pengarsipan data-data barang ke dalam database, mampu memudahkan perusahaan dalam mengolah data-data barang untuk produksi barang, mampu mengidentifikasikan apakah data barang yang masuk dan keluar sesuai dengan batas minimum kebutuhan perusahaan (sebagai proses pengambilan keputusan), mampu memberikan efisiensi dan efektifitas ketepatan data dalam perumusan laporan ke tingkat direktur utama, mampu memudahkan perusahaan dalam mengkomunikasikan arus data dari dan ke 
setiap bagian perusahaan dan mampu memberi kemudahan dalam pengoperasian sistem untuk end user.

\section{Analisis Sistem Berjalan}

Sistem berjalan pada bagian produksi adalah sebagai berikut: kantor manajemen PT. ABC memiliki gudang yang terpisah sehingga memerlukan waktu perjalanan dari gudang ke kantor, system inventory ditekankan untuk bagian produksi yang mengolah, mengatur persediaan, memberikan laporan kondisi produk dan pasokannya kepada direktur utama.

\section{Analisis Sistem Usulan}

Pada Sistem yang diusulkan terdapat 3 pengguna sistem, yaitu: user dir_utama yang memiliki akses untuk melihat laporan data barang masuk dan keluar, data supplier, data pembeli dan laporan data ready stock yang tersedia digudang, User adm_gudang yang memiliki hak akses untuk menginput datadata barang masuk dan keluar, data supplier, data pembeli dan menginput data sortir barang yang dilakukannya serta User front_desk yang memiliki hak ases pada sistem ini hanya untuk mengecek ketersediaan barang di dalam gudang.

Pada tahapan menggunakan Argo Unified Modelling Language (ArgoUML) sebagai alat untuk menggambarkan model sistem inventori yang dijalankan.

\section{Diagram Input Output}

Suatu sistem diharapkan dapat mengolah masukan menjadi keluaran yang digambarkan pada diagram Input Output. Diagram input dan output sistem inventori untuk memperjelas perancangan sistem dapat dilihat pada Gambar 3.

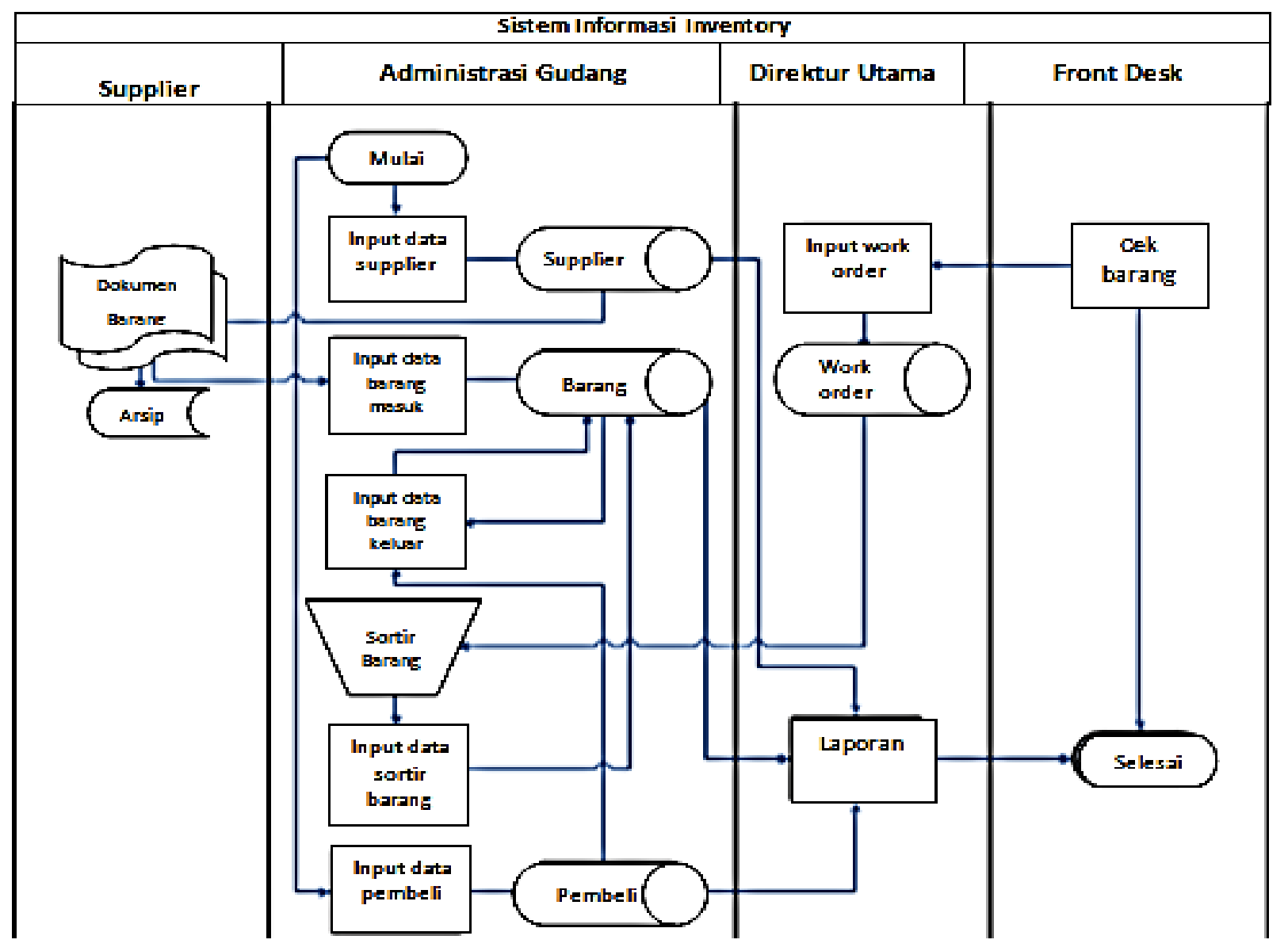

Gambar 2. Block Diagram Sistem Informasi Inventori Usulan 


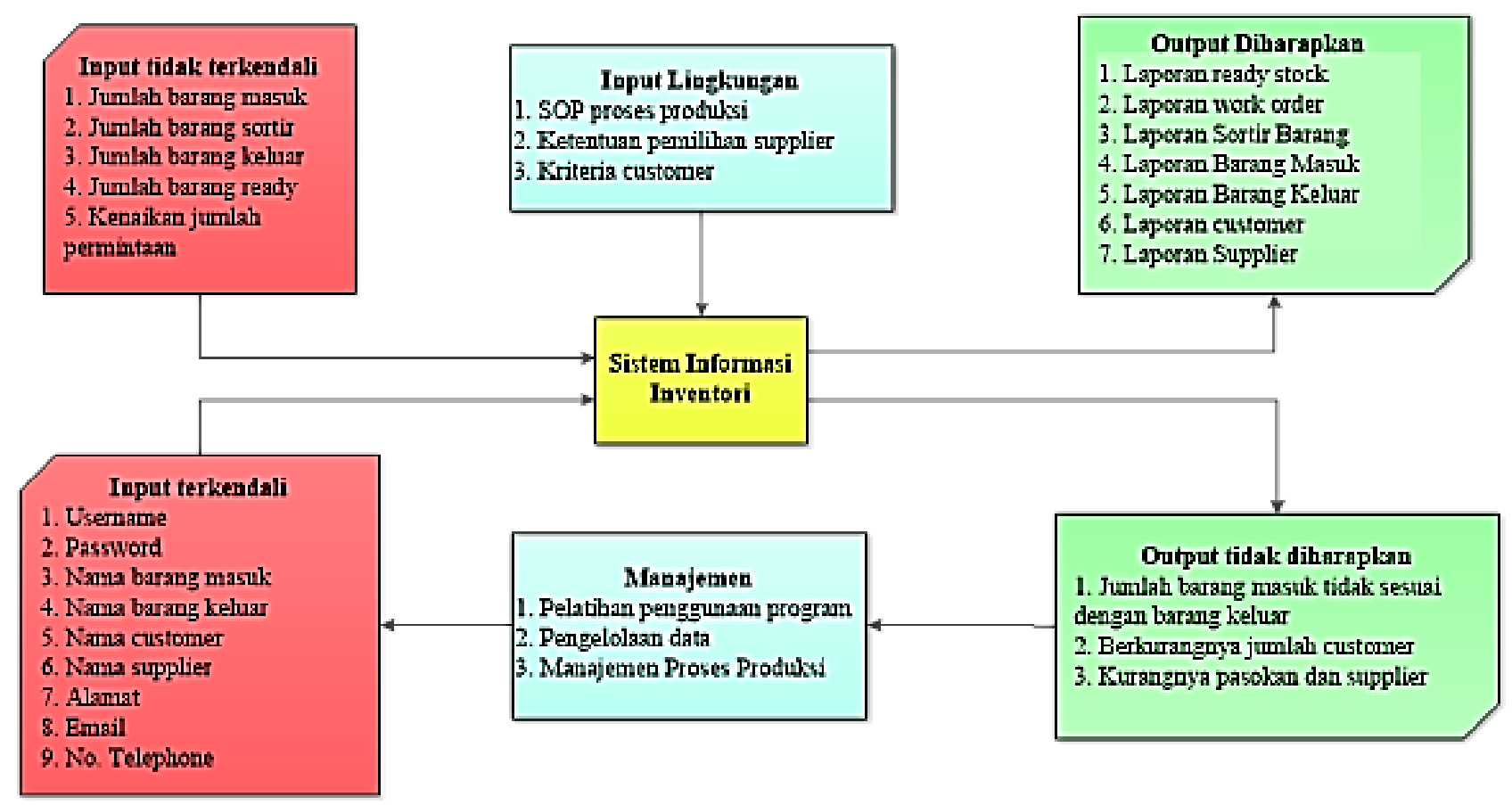

Gambar 3. Diagram Input dan Output Sistem Inventori

\section{Causal Loop Diagram}

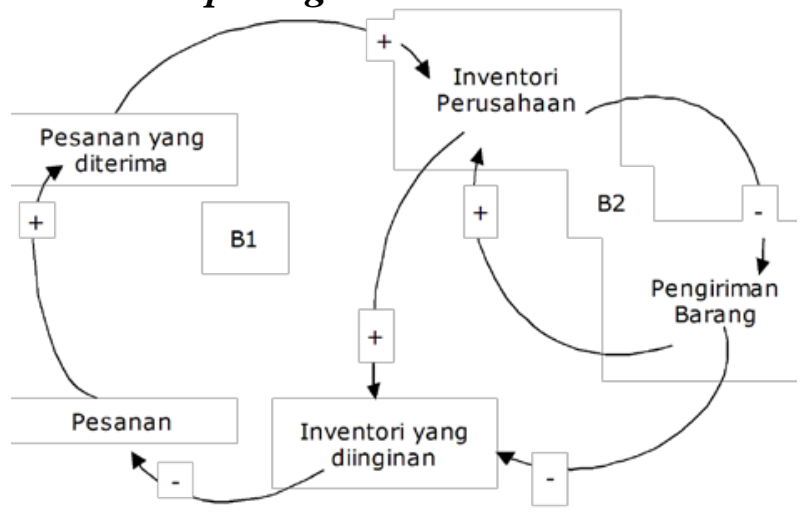

Gambar 4. Causal Loop Diagram Sistem Inventori

Causal loop diagram pada Gambar 4 menunjukkan dua balancing (negatif) loop umpan balik (B1 dan B2), dimana B1 menunjukkan hubungan sebab akibat antara pesanan yang diterima dan tingkat persediaan, sedangkan B2 menunjukkan hubungan antara tingkat persediaan dan pengiriman dilakukan.

\section{HASIL DAN PEMBAHASAN Identifikasi Permasalahan}

Pada sistem yang berjalan saat ini, semua user melakukan perintah kerja dan segala kegiatan pelaporan dilakukan dengan manual. Berikut permasalahannya:
- Pencatatan masih menggunakan kertas lalu dipindahkan ke dalam komputer, serta masih stand alone.

- Kebutuhan karyawan atas pelayanan yang memerlukan proses yang cepat dan tepat.

- Pengolahan laporan berkala untuk direktur utama masih terbatas karena tidak dapat dilakukan sewaktu-waktu.

\section{Desain Sistem (Design)}

Perancangan sistem dilakukan untuk menghasilkan sistem baru dengan teknologi terbaru untuk mengurangi dan mengatasi berbagai permasalahan yang ada di sistem yang lama sehingga dapat meningkatkan efektifitas dan efisiensi. Daftar properti entitas dapat dilihat pada Tabel 3.

\section{Perancangan Program}

Dalam perancangan sistem, diggunakan UML (Unified Modelling Language) sebagai tools untuk perancangan dan pengembangan aplikasinya, seperti Use Case Diagram, Activity Diagram, Narrative Activity Diagram, Sequential Diagram, Class Diagram dan Tabel Database pada Microsoft Access.

\section{Use Case Diagram}

Use case adalah sebuah alat bantu guna 
menstimulasi pengguna untuk mengatakan tentang suatu sistem dari sudut pandangnya.

Dalam sistem ini terdapat aktor manajemen yang dapat mengakses beberapa pilihan yaitu melihat list dan menginput data dari item, supplier, customer, ingoing stock, dan outgoing stock, serta melihat stock report keseluruhan. Use case diagram pada Gambar 7 menggambarkan tingkah laku dari aktor manajemen setalah masuk ke dalam menu yang diaksesnya.

Tabel 3. Daftar Properti Entitas

\begin{tabular}{cl}
\hline Entitas & \multicolumn{1}{c}{ Atribut } \\
\hline Produk & Nama Produk, Design, Size, Colour, Kode Harga \\
Direktur Utama & Nama Direktur, Alamat Direktur, Telp Direktur \\
Admin Gudang & Nama Admin, Alamat Admin, Nomor Induk Karyawan \\
Supplier & Nama Supplier, Alamat Supplier, Telp Supplier \\
Customer & Nama Customer, Alamat Customer, Telp Customer \\
Front Desk & Nama Front Desk, Alamat Front Desk, Nomor Induk Karyawan \\
Distributor & Nama Distributor, Konsinyasi, Alamat Distributor, telp Distributor, Pemilik \\
\hline
\end{tabular}

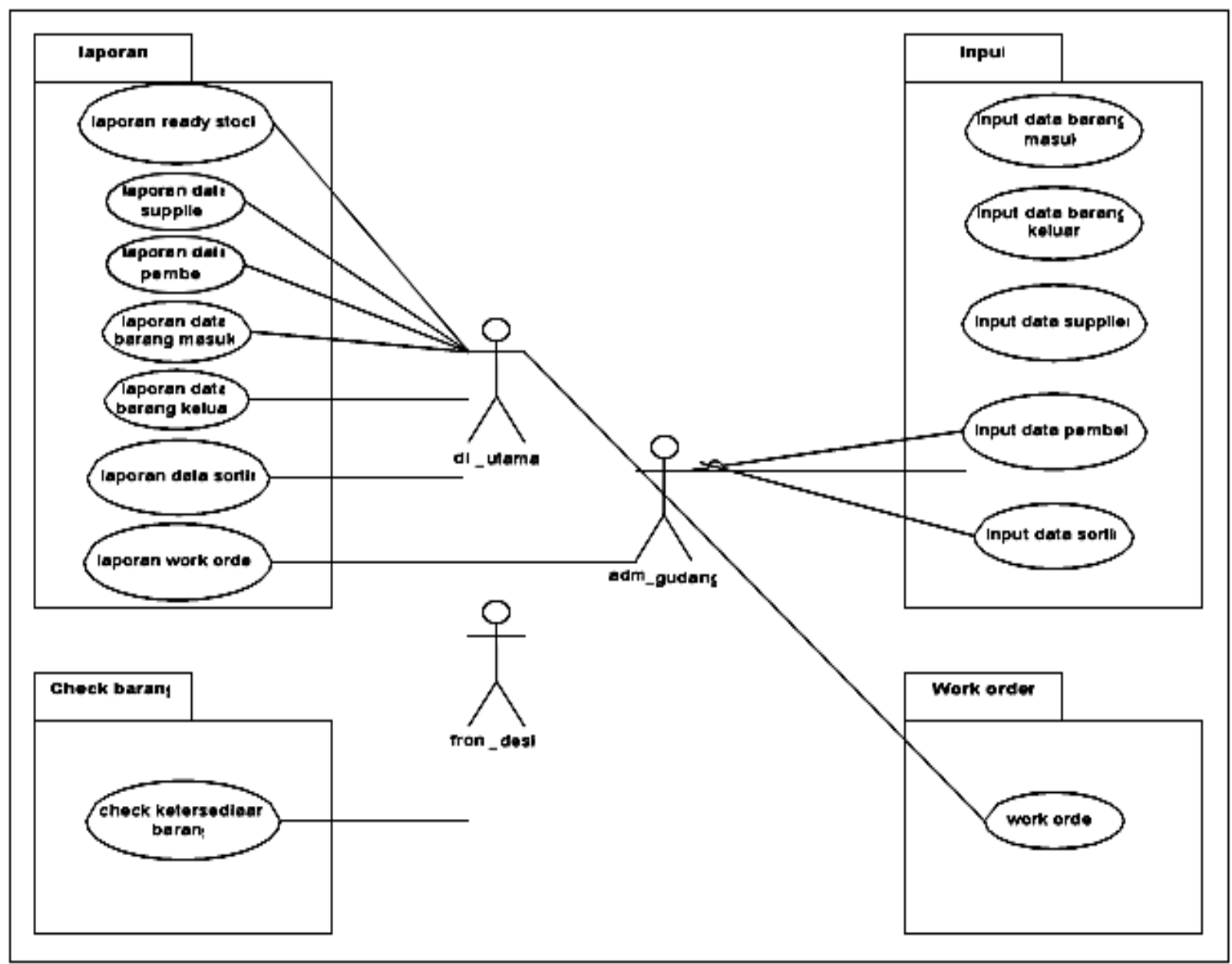

Gambar 5 Use Case Diagram Inventori 


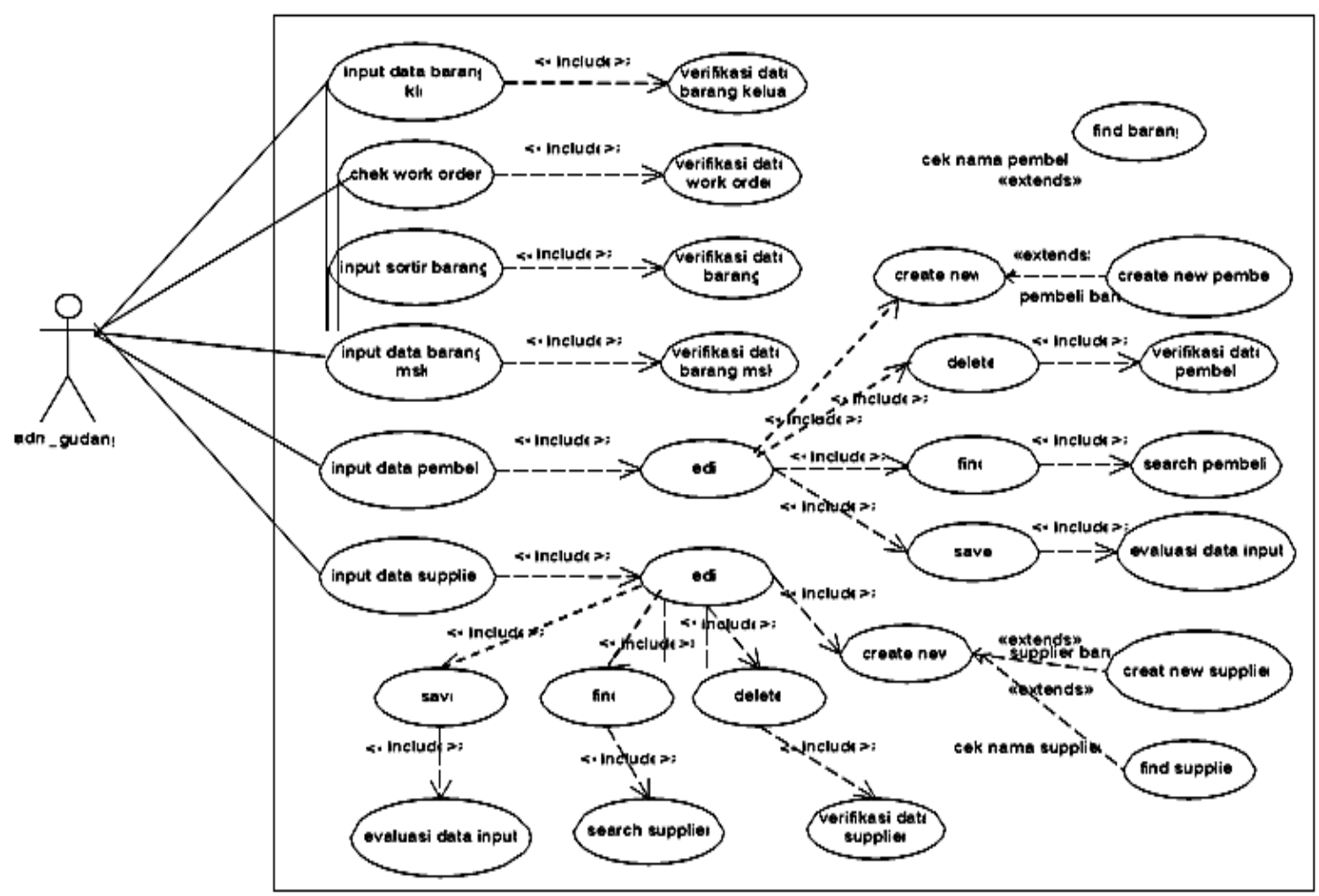

Gambar 5 High Level Use Case Diagram

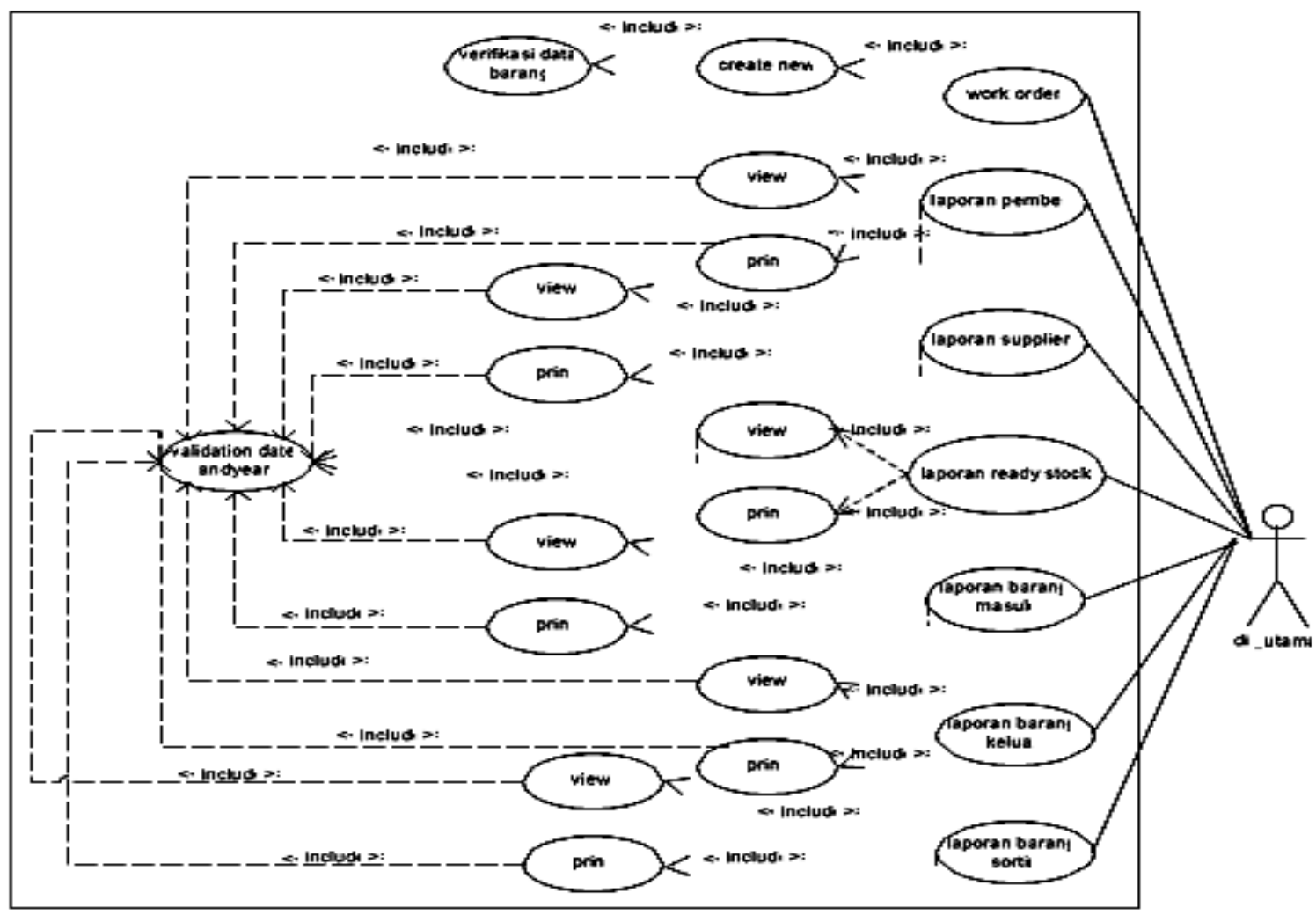

Gambar 6 High-level Use Case Sistem Inventori dir_utama actor

\section{Activity Diagram}

Tampilan tahapan aktivitas user administrasi gudang dalam penggunaan sistem informasi ini, dapat dilihat pada Gambar 7. 
Activity diagram pada Gambar 7, penggunaan aplikasi sistem informasi ready menampilkan aktivitas tiap user dalam stock data barang dapat dilihat pada Gambar 9. penggunaan sistem informasi. Penggunaan Dalam diagram aktivitas tersebut, menunjukkan aplikasi sistem informasi output data barang aktivitas yang harus dilakukan oleh user dan dapat dilihat pada Gambar 8.

Activity diagram pada Gambar 8 menampilkan aktivitas tiap user dalam penggunaan sistem informasi. Sedangkan bagaimana interaksinya terhadap sistem digambarkan secara bertahap sesuai dengan tahapan kegiatan yang dilakukan.

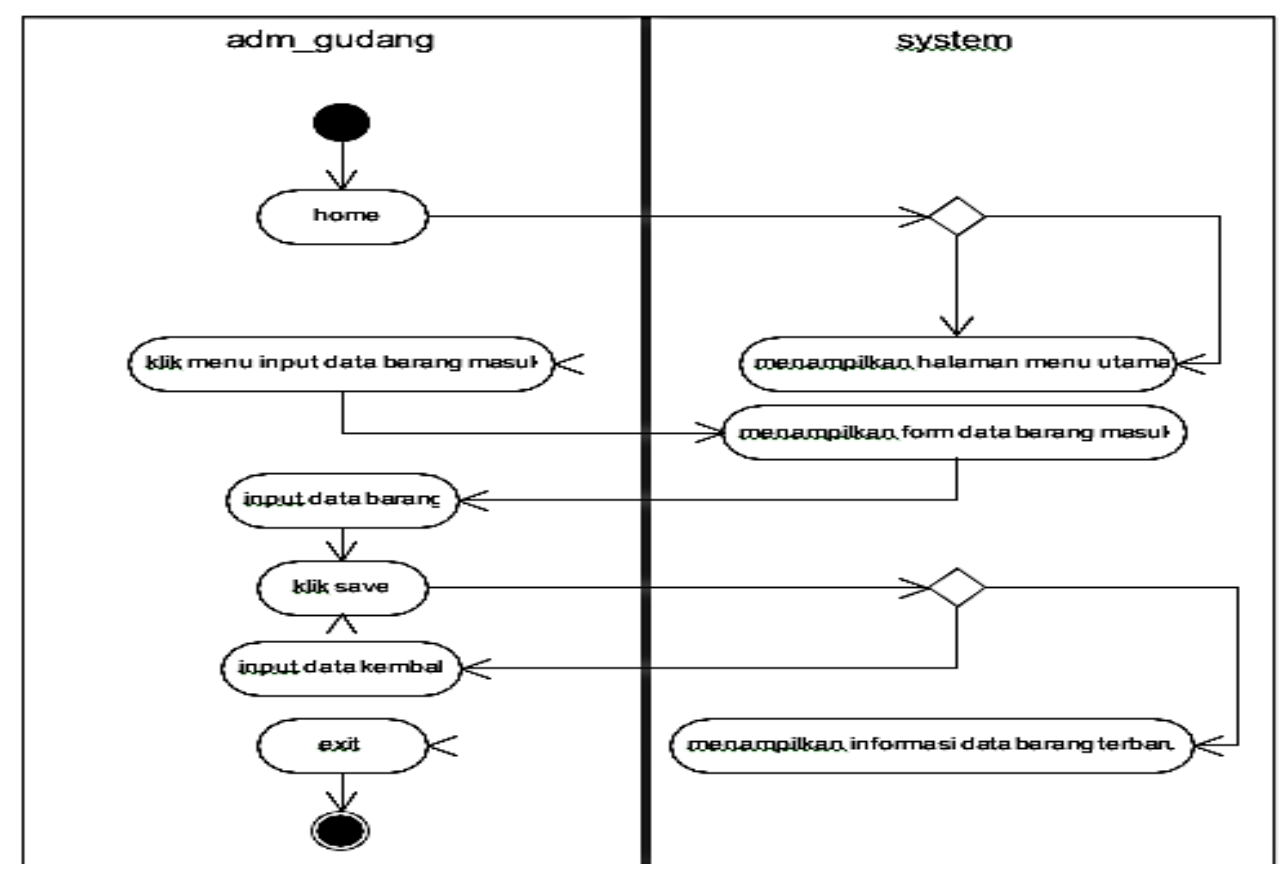

Gambar 7 Activity Diagram untuk Input Data Barang Masuk

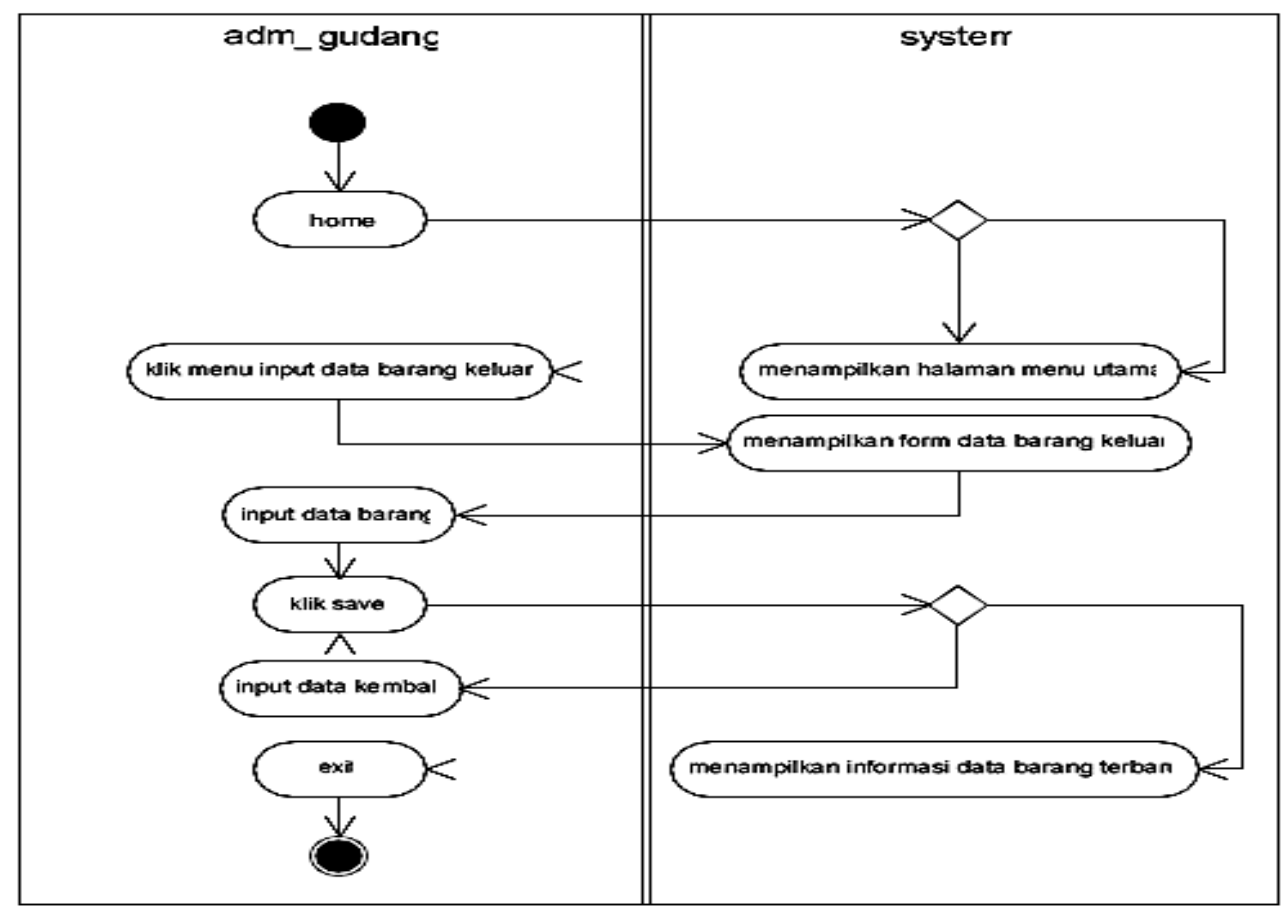

Gambar 8 Activity Diagram untuk Input Data Barang Keluar 


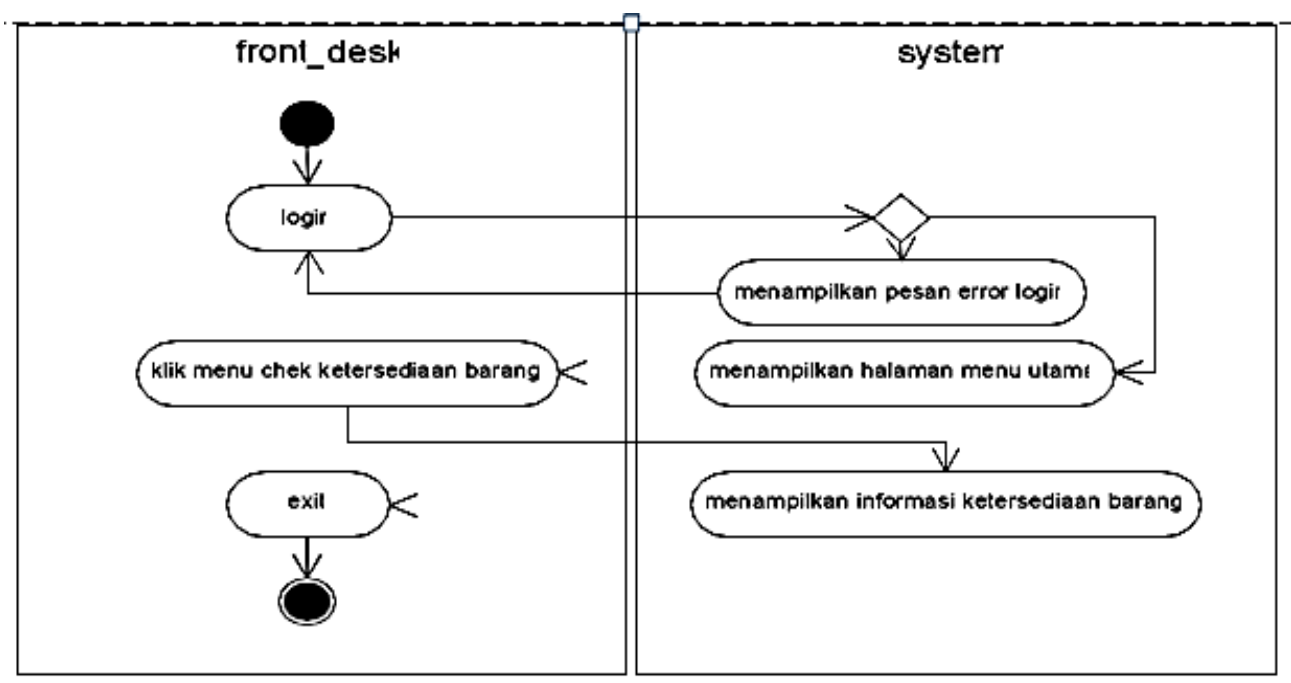

Gambar 9. Activity Diagram untuk Laporan Ready Stock

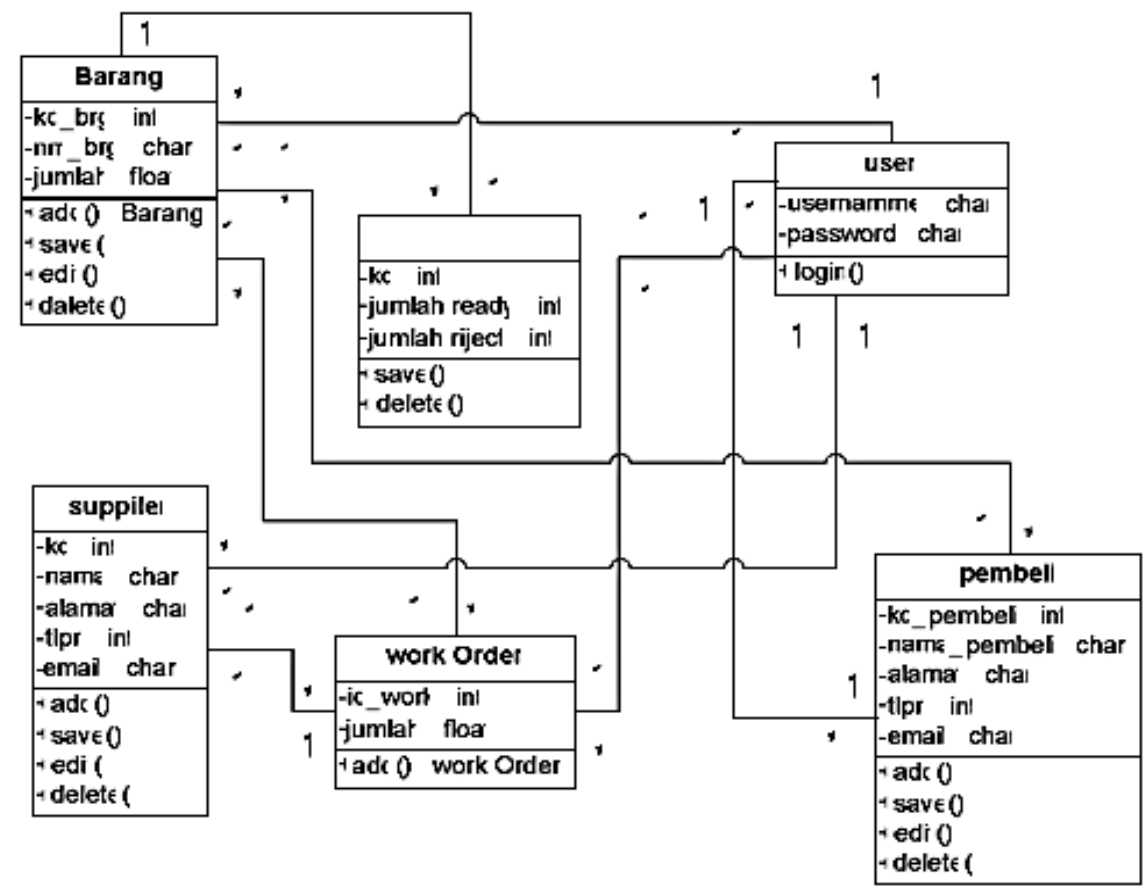

Gambar 10. Class Diagram

\section{Class Diagram}

Diagram ini adalah deskripsi kelompok objek-objek dengan prototype, perilaku dan relasi yang sama. Class diagram yang digunakan seperti pada Gambar 10.

\section{Implementasi}

Implementasi sistem menggunakan XAMPP versi 5.6.3 yang mencakup: Apache versi 2.2.4 untuk web server, PHP versi 5.6.3. Selain itu, juga menggunakan Atom sebagai software text editor, MySQL versi 5.6.21 sebagai database management-nya dan, serta menggunakan ArgoUML untuk tools UML. Selain itu juga sarana pendukung yang diperlukan agar sistem dapat berjalan sesuai yang diharapkan.

\section{Data Flow Diagram (DFD)}

Data Flow Diagram (DFD) digunakan untuk menggambarkan suatu sistem secara menyeluruh. Gambar DFD level 0 dan 1 dapat dilihat pada Gambar 11 dan 12.

Dalam data flow diagram level 0 , merupakan penjelasan arus data diantara user dari sistem informasi inventori yang akan 
diterapkan, sedangkan data flow diagram level 1 akan menjelaskan secara detail arah data yang digunakan serta tahapan aliran data yang akan digunakan dalam sistem informasi yang dibuat.

\section{ERD (Entity Relationship Diagram)}

Gambar entity relationship diagram sistem inventori dapat dilihat pada Gambar 13.

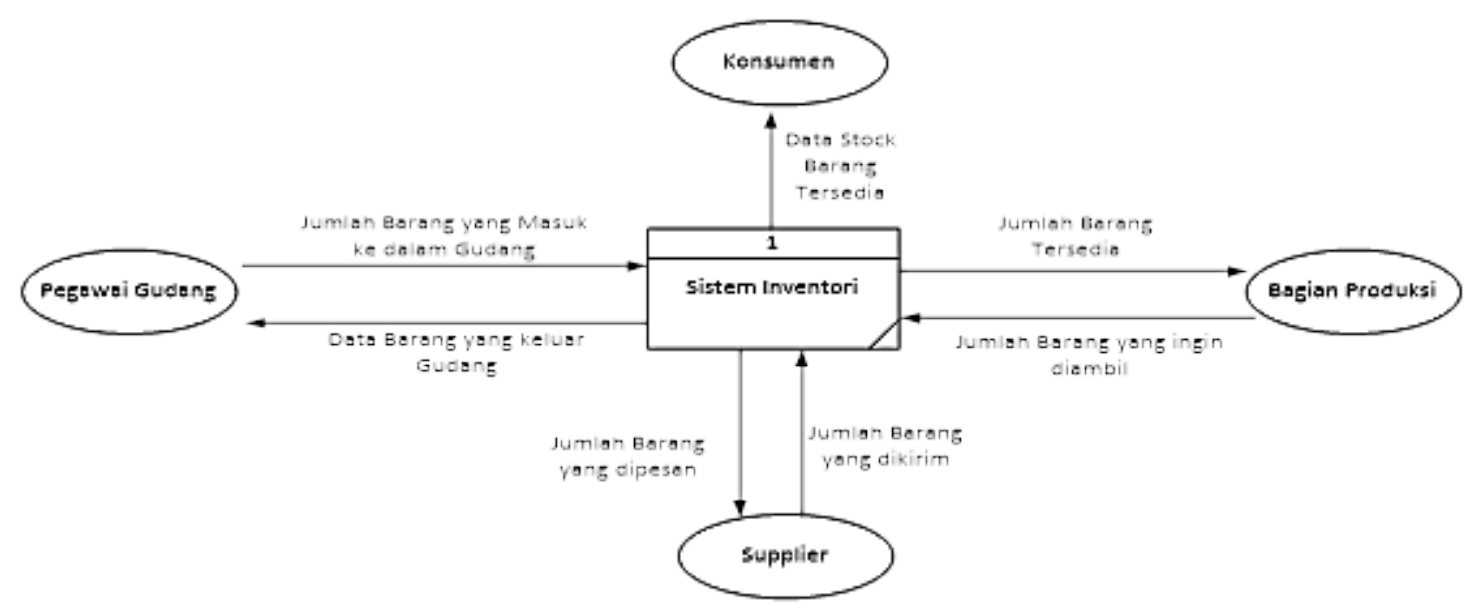

Gambar 11. Data Flow Diagram Level 0

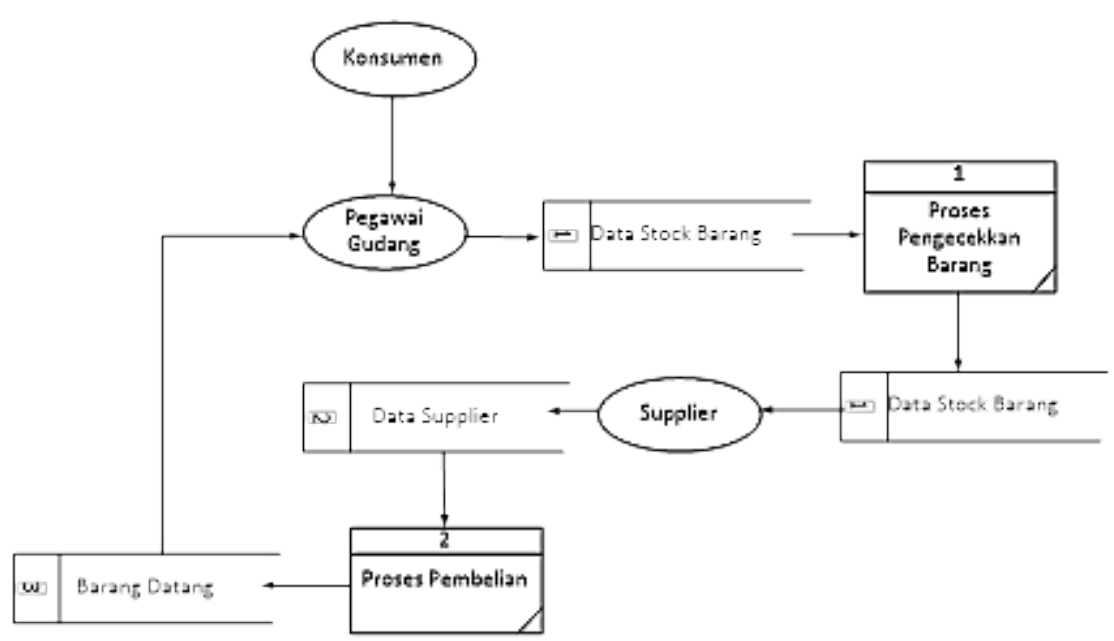

Gambar 12. Data Flow Diagram Level 1

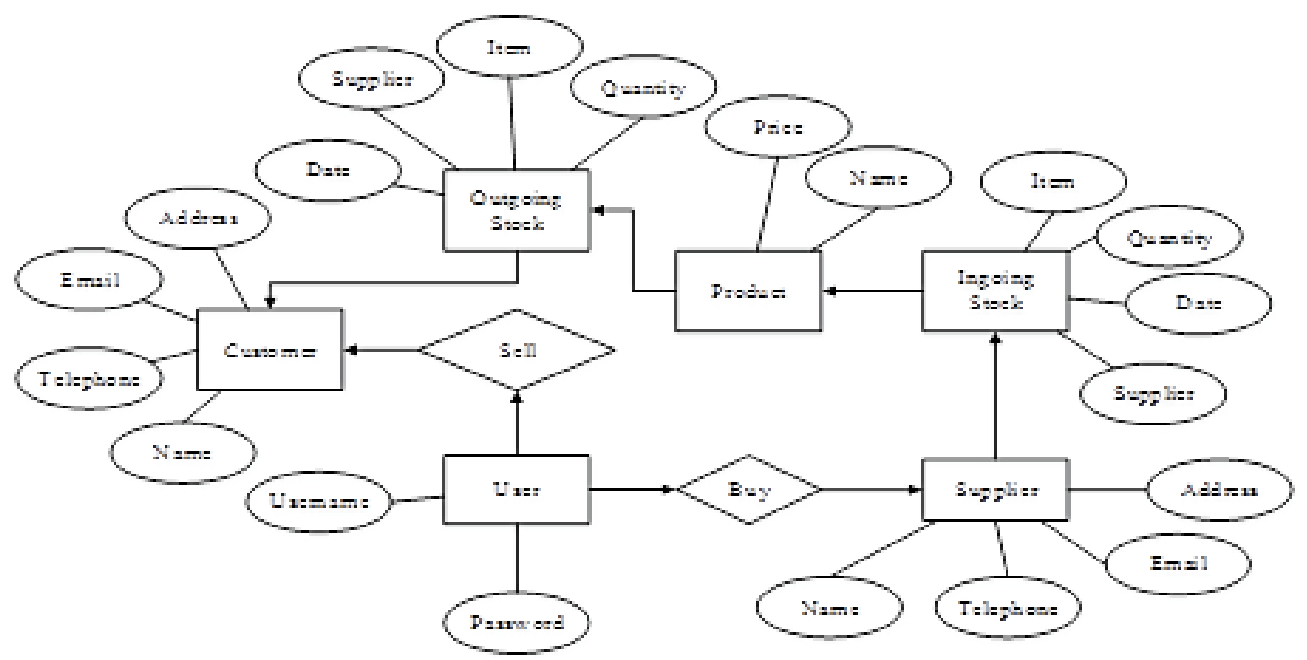

Gambar 13. ERD Sistem Inventory 
Entity Relationship Diagram menggambarkan hubungan antar entitas yang terlibat dalam interaksi penggunaan sistem informasi yang akan diterapkan. Selain menggambarkan hubungan diantara entitas, ERD juga menggambarkan data-data apa saja yang untuk mengelola sistem informasi yang diperlukan perusahaan.

\section{Coding}

Perancangan coding dibuat dengn program software editor Atom, dan dibuka dalam local host PHP dan Perancangan tampilan dibuat dalam local host xampp.

\section{Tampilan Input Customer}

Tampilan input customer akan berisi mengenai nama customer dan kontak customer yang dapat dihubungi. Kontak tersebut meliputi nomor telpon, alamat email, dan alamat pengiriman barang yang akan dipesan oleh customer tersebut, sehingga perusahaan memiliki track record data customer yang lengkap dan jelas sehingga jika suatu hari perusahaan memiliki strategi pemasaran baru, dapat ditawarkan ke customer perusahaan tersebut langsung melalui kontak yang terekam dalam sistem informasi tersebut.

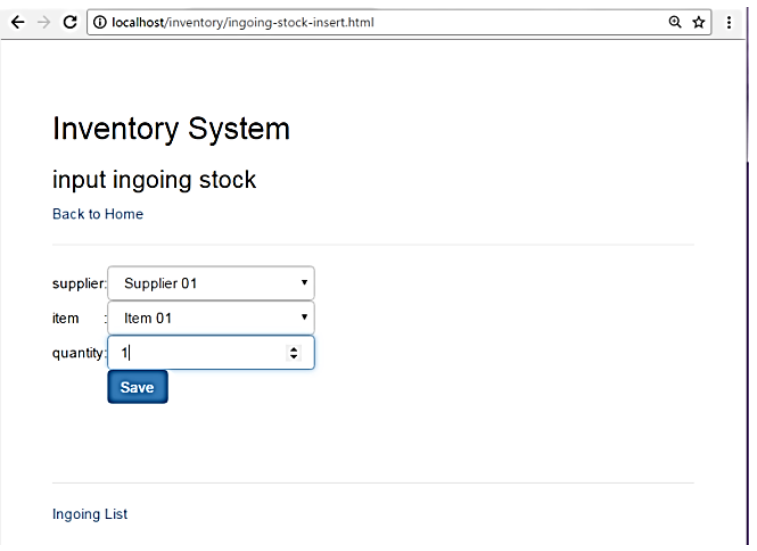

Gambar 14. Tampilan Input Ingoing Stock

Input ingoing stock adalah tampilan stok barang yang masuk ke dalam gudang. Sebelum petugas administrasi gudang memasukkan barang ke dalam gudang, barang yang masuk harus di cek terlebih dahulu dan didaftarkan melalui tampilan input ingoing stock ini. Sehingga pihak manajemen dapat melihat barang pa saja yang sudah masuk dan sistem kemudian dapat menghitung secara otomatis jumlah barang yang tersedia di dalam gudang saat ini.

\section{Inventory System}

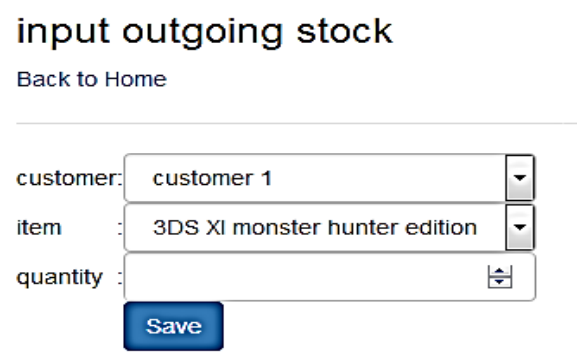

Outgoing List

\section{Gambar 15. Tampilan Input Outgoing Stock}

Input outgoing stock digunakan untuk mendaftarkan barang yang keluar dari gudang. Petugas administrasi barang akan menuliskan barang apa saja dan berapa jumlah barang yang keluar dari gudang. Untuk merekam jejak barang yang keluar, petugas juga harus menuliskan kemana barang itu akan dikirimkan. Sehingga nantinya, sistem ini dapat dihubungkan ke dalam sistem pengiriman barang yang telah dipesan oleh customer sebelumnya.

\section{Tampilan Stock Report}

Dari seluruh tampilan di atas, keunggulan lain yang dimiliki sistem ini adalah, sistem ini memiliki tampilan stock report yang lengkap, sehingga tim manajemen dapat melihat data secara jelas, mendetail dan menyeluruh mengenai rekap jumlah barang yang tersedia saat ini, dan barang apa saja yang paling sering dipesan oleh customer. Tim manajemen juga dapat melihat customer mana saja yang sering membeli barang dari perusahaan. Langkah kedepannya, tim manajemen dapat mempersiapkan pengembangan perusahaan melalui perencnaan strategis yang paling menguntungkan bagi masa depan perusahaan. Ketika user memilih pilihan untuk melihat stock report maka akan muncul tampilan seperti pada Gambar 16. 


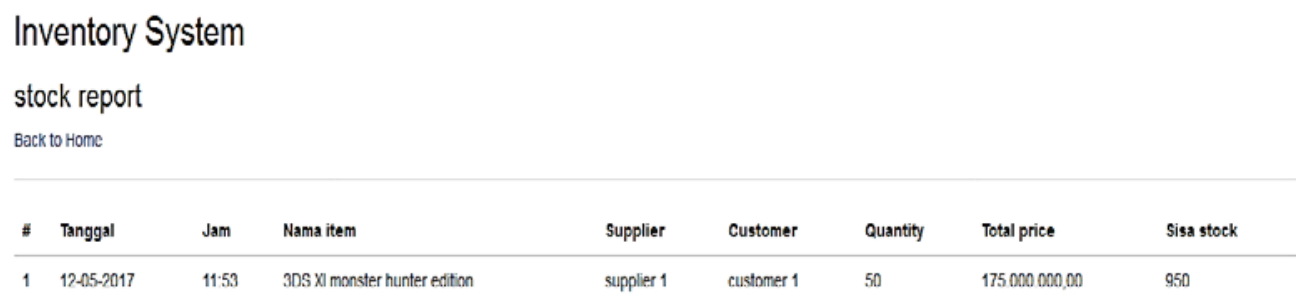

Gambar 16. Tampilan Stock Report

Dengan adanya sistem informasi inventori ini, perusahaan menjadi lebih mudah untuk melakukan arsip data-data, terutama untuk data customer dan data supplier yang sering membeli/mengirim barang dari dan ke perusahaan ini. Selain itu, histori barang yang masuk dan keluar gudang tersebut dapat tercatat dengan rapi dalam sebuah sistem terintegrasi. Tim manajemen perusahaan dapat mulai merancang strategi perkembangan perusahaan dalam jangka panjang, sebab data terbaru mengenai keadaan gudang sekarang ini dapat secara langsung diakses, sehingga direktur utama atau tim manajemen tidak perlu lagi mencari dan/atau mengolah historis data secara manual. Efisiensi waktu, tenaga dan produktivitas perusahaan pun secara tidak langsung akan meningkat.

\section{KESIMPULAN}

Kesimpulan implementasi sistem inventori dengan program PHP yang digunakan dalam sistem inventori yaitu: sistem informasi inventori berbasis web, mempercepat pembuatan laporan stok barang tanpa merekap ulang data. Setiap pengguna mempunyai hak akses untuk mengelola sistem informasi inventori, agar dapat diketahui dengan mudah pengguna yang salah dalam pengelolaan data inventori. Memberikan kemudahan kepada pengguna dalam pengelolaan data dalam waktu yang bersamaan karena dibuatkan sistem web base.

\section{DAFTAR PUSTAKA}

[1]. Borroel, Maria Rosario. 2014. Perancangan Sistem Informasi Manajemen Aset Pada Stikom Dinamika Bangsa Jambi (Studi Kasus: Penjualan
Dan Disposal Aset Tetap). Sekolah Tinggi Ilmu Komunikasi Dinamika Bangsa, Jambi. http://mediasisfo.stikom-db.ac.id (diakses pada tanggal 15 Juni 2017)

[2]. Susanto, Arisma. 2010. Pengembangan Sistem Informasi Inventori pada PT. Dwiwarna Inti Sejahtera. Universitas Islam Negri, Jakarta. http://repository.uinjkt.ac.id/dspace/bitstre am/123456789/2014/1/ARISMA\%20SUS ANTO-FST.pdf (diakses pada tanggal 22 April 2017)

[3]. Anggadini, Sri Dewi. 2011. Analisis Sistem Informasi Manajemen Berbasis Komputer dalam Proses Pengambilan Keputusan.

http://jurnal.unikom.ac.id/_s/data/jurnal/v olume-11-2/02-miu-11-2-sridewi.pdf/pdf/02-miu-11-2-sri-dewi.pdf (diakses pada tanggal 15 Juni 2017)

[4]. Utami, Sri, Setyaningsih. 2013. Peranan Sistem Informasi Manajemen Untuk Pengambilan Keputusan Pengusaha Kecil Universitas Slamet Riyadi, Surakarta https://media.neliti.com/media/publication s/23335-ID-peranan-sistem-informasimanajemen-untuk-pengambilankeputusan-pengusaha-kecil.pdf (diakses pada tanggal 15 Juni 2017)

[5]. Sami, Mohammed. 2011. Quality of Information as Strategic Factor in Accounting Information System (AIS) towards better organizational performance. Universitas Utara Malaysia, JRMSI, Vol. 2, Hal:1-17

[6]. Subchan. 2014. Peranan Strategi Sistem Informasi Manajemen Untuk Mencapai Tujuan http://ito_riris.staff.gunadarma. ac.id (diakses pada tanggal 15 Juni 2017) 